\title{
A Survey on Data Dissemination Protocols used in VANETs
}

\author{
Navneet Kaur \\ M.Tech Research Scholar \\ Department of Computer Science and Engineering \\ Amritsar College of Engineering \& Technology, \\ Amritsar
}

\author{
Amarpreet Singh \\ Associate Professor \\ Department of Computer Science and Engineering \\ Amritsar College of Engineering and Technology, \\ Amritsar
}

\begin{abstract}
Vehicular Adhoc Network (VANET) is a form of Mobile Adhoc Network (MANET) in which vehicle nodes act as router as well as host for propagating information among nearby vehicles and nearby fixed road side equipments which improves the efficiency and quality of driving in terms of safety, time and speed. In VANETs, it is necessary to route information efficiently from source to destination in order to avoid collisions, accidents and traffic jams etc. In this paper, we have reviewed various data dissemination protocols which define the way to transfer information in highway and urban scenarios with minimum propagation delay, redundancy and acknowledgments give the assurance of message has reached its destination successfully.
\end{abstract}

\section{Keywords}

Vehicular adhoc network; Data Dissemination Protocols; Data Dissemination

\section{INTRODUCTION}

Vehicular Adhoc Network (VANET) is a form of Mobile Adhoc Network (MANET), where mobile nodes are vehicles [5]. VANETs provide wireless communication between vehicles and road side equipments [1]. Vehicles that are in radio range of each other can communicate with one another. In VANETs, delivery is not single hop rather multihop delivery is done and even the vehicle which is miles away from destination can also send their request like- traffic conditions, obstacle information can be obtained by the vehicles when they are currently not in the city [3]. VANETs are distributed, self-organized and potentially highly mobile networks of vehicles interacting via wireless media [2].

In Vehicular adhoc networks, there is very high mobility in which each vehicle node act as a router as well as host and sending packets to other mobile nodes and changing their topology very fast [3]. In Vehicular adhoc networks topology keeps on changing and also vehicles are not always connected to the network. There are frequent disconnections in VANETs. Therefore, routing protocols used in MANETs are not necessarily be suitable for VANETs as in MANET's protocols there is an implicit assumption of network connectivity [2,3]. Intermittent connectivity, frequent changes in network topology and low reception rate are those properties that distinguish VANETs from other types of adhoc networks [2].

Routing can be defined as finding optimal path between source and destination node and then sending message on that path so that message can reach its destination easily, quickly and on time. The main problem that needs to be solved in
VANETs is how to exchange information in scalable fashion [4]. The answer lies in Data Dissemination Protocols. Data Dissemination Protocols differ from one another in terms of that some of them are used in highway while others are used in urban areas and some can be used in both scenarios.

As in case of urban areas there are many number of intersection points and in large cities buildings can block communication among nearby vehicles though they are in transmission range of each other. So, it becomes necessary to forward information to those vehicles or Road Side Units (RSU) that are close to intersections so that information packets should not be lost due to obstacles such as buildings.

Therefore, Protocols that are used for disseminating data in urban areas may differ from those that are used for propagating information on highways as highways shows one dimensional topology.

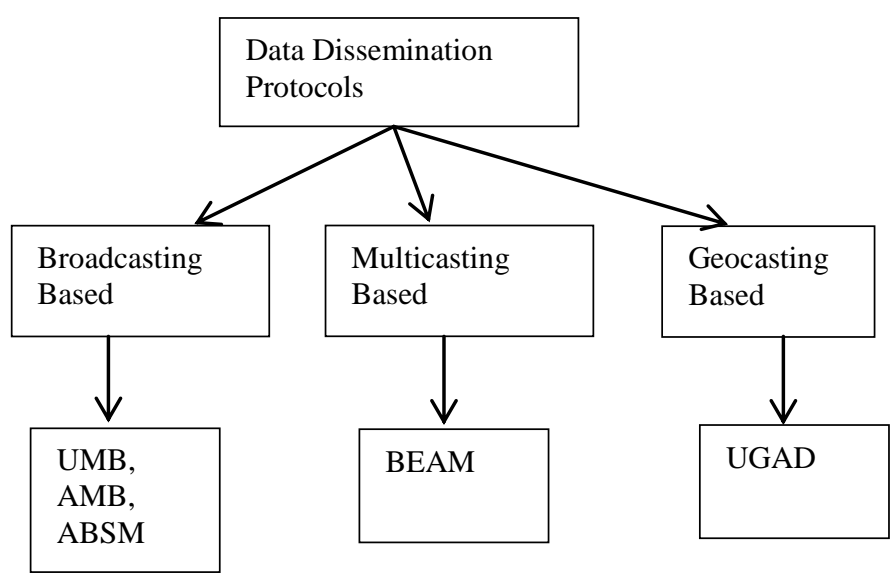

Figure1. Data Dissemination Protocols

\subsection{Challenges in VANETS:}

i) Multihop data delivery is challenging task as frequent disconnections and high mobility is there in VANETs [3].

ii) Gathering of information like accident, speed limit, obstacle information, and traffic conditions etc. for safety and entertainment convenience purpose [3]

iii) Vehicles should be chosen for data delivery in such a way that packets will be transmitted with minimum delay to destination. [3]. 


\subsection{Applications of VANETs:}

There are three main applications of VANETs that are given below:

\section{i) Safety Applications:}

Safety applications are one of the most important applications type which is primarily focused on to reduce the chances of road accidents and the loss of life of the occupants of vehicles. A large number of accidents that happen in all parts of the world are associated with vehicle collisions. This class of applications mainly provides active road safety to avoid collisions by assisting the drivers with timely information. Information is shared among vehicles and road side units which is further used to predict vehicle collisions [16].

ii)

\section{Traffic Monitoring and Management} Applications:

This category primarily focuses on improving the vehicle traffic flow, traffic coordination and traffic assistance. It is responsible for providing updated local information, maps and relevant messages bounded in space and/or time [16].

\section{iii) Infotainment Applications:}

Infotainment applications provide convenience and comfort to drivers and passengers. The idea of infotainment applications intend to provide all kind of messages that offer entertainment and useful messages to the driver and passenger. Finding the nearest coffee shop, cinema, mall, fuel station which offers the best price in that area, or available parking spot are the few examples of infotainment applications [16].

\subsection{Characteristics of VANETs:}

In addition to the similarities to ad hoc networks, VANETs possess unique network characteristics that distinguish it from other kinds of ad hoc networks and influence research in this area [16]. Few important characteristics of VANETs are as follows:

- Somewhat predictable but Highly Dynamic Topology

- Mobility Modelling and Predication

- Geographical Type of Communication

- Different Communication Environments

- Adequate Storage and Energy

- Frequent Network Disconnection

\section{BACKGROUND}

\subsection{VANET Architecture:}

As shown in Figure 2, data dissemination in VANET depends upon three architectures:

i)
V2V: This is vehicle to vehicle architecture where vehicles act as both consumers and producers as vehicles receive information from other vehicles in the network and distribute that information to other vehicles in the network. So, both collection and distribution of data are done within the network for faster delivery of messages [7].

V2I: This is vehicle to infrastructure wireless architecture in which infrastructure is used to collect information from vehicles and provide that information to other vehicles when necessary [7].

iii) Hybrid: This is combination of both V2V and V2I architectures [7].

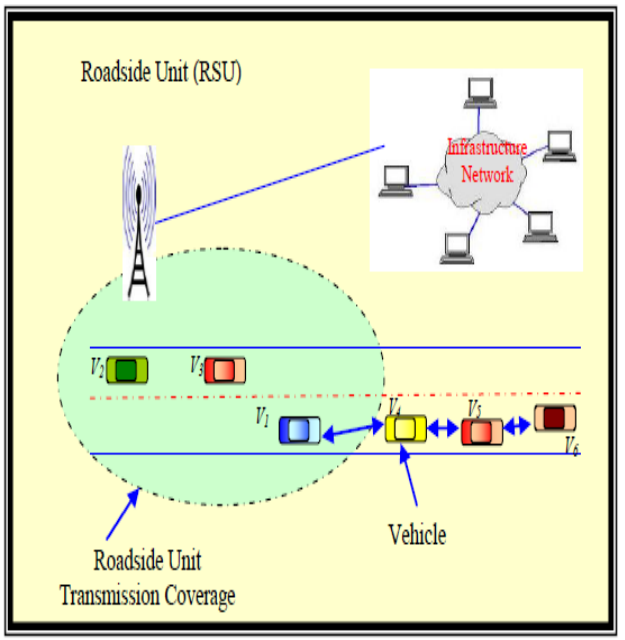

Figure 2: Vehicular Communication Architecture [16].

\subsection{Challenges in Data Dissemination:}

Data dissemination is a process of spreading data or information over distributed networks [1]. So, data dissemination in VANETs improves the efficiency of traffic system. It also improves the quality of driving. Though this process seems to be very simple but in reality it is tough for vehicles to communicate among themselves due to large number of vehicles on road. So, it becomes very challenging task for vehicles to transmit information over the network [7]. Some of the main issues during dissemination of data are:

i) High Mobility and Frequent Disconnections: The big challenge in VANETs is the high mobility and frequently disconnected topology at different regions of the city. The traffic density is low during the night and in suburban areas, but network node density is very high in urban areas and especially during the peak hours in day time, which causes frequently network disconnection. There is no simple 'one-for-all' solution for disseminate data to all recipients spreading across the city [1].

ii) Data Transmission in presence of Disconnection:

The second main challenge in VANETs how to disseminate data over the network with less delay and before occurring the disconnections among vehicles. When target vehicle moves closer to the roadside unit and placed in densely area, disconnection is less concern. But the major problem is when different vehicles those are in radio range of one another requesting the same data at the same time and sharing the wireless media then utilization of bandwidth is the key issue. When a vehicle reaches within the one-hop range of the road side units, data can be transmitted to the vehicle at the highest throughput. Thus a vehicle passes by the roadside unit, it is most desirable to extend the connection time between the vehicle and road side unit so as to spread more data [1].

iii) Data Distribute over the Mesh Nodes:

For efficient data dissemination, many roadside units are connected together to form an infrastructure like mesh network and cooperatively disseminate data to the vehicles. 
So, it becomes very difficult how to distribute data in the mesh network [1].

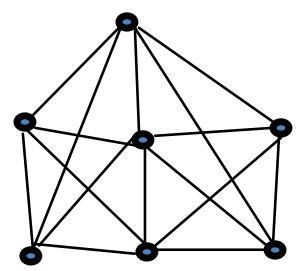

Figure3. Mesh Network

\subsection{Types of Data Dissemination}

Data Dissemination is a process of spreading data or information over distributed wireless networks. Aim of data dissemination is the optimum use of network resources to serve the data needs of all users [1]. Different types of data dissemination used in VANETs are:
i)
V2I/I2V Disseminati
infrastructure or RSU)
ii) V2V Dissemination (Vehicle to vehicle)
iii) Opportunistic Dissemination
iv) Peer-to-peer Dissemination
v) Cluster Based Dissemination

\section{i) V2I/I2V Dissemination:}

It consists of two types of mechanisms: Push based and pull based. In Push based data dissemination, data pouring and buffering concepts are used. With data pouring concept, road is selected having high mobile vehicles and data center broadcast the data to the vehicles on the same road as well as on crossing roads. Data center is a computer having wireless interface that collects the data from outside world and deliver it to the vehicles. And buffers are placed at intersection points to store the data and from these buffers data will be transmitted to moving vehicles [3]. So, in push based data dissemination, data is efficiently delivered from the moving vehicles or RSUs (Road Side Units) to another vehicle [1]. While pull based data dissemination scheme is used by vehicles if they want to get some information from data center or from some other vehicles. This scheme is mainly used by vehicles for making queries and receiving response [3].

\section{ii) V2V Dissemination:}

In vehicle to vehicle data dissemination flooding and relaying mechanisms are used [1]. In flooding, data is broadcasted to all nodes that participate in data dissemination. One to all communication is done here. In the relay type of data dissemination, relay node is selected and this node forward the data to next relay hop and so on. Relay approach is generally preferred for congested networks [1].

\section{iii) Opportunistic dissemination:}

In opportunistic data dissemination, messages are stored at each intermediate node and forwarded to every encountered node till the destination is reached [1].

\section{iv) Peer-to peer Dissemination:}

In P2P dissemination, the source node stores the data in its storage device and sends the data in the network only when it is demanded by another node [1]. v) Cluster Based Dissemination:

In order to reduce broadcast storms and for providing better delivery ratio, a data packet has to be relayed by a minimum of intermediate nodes to the destination. To do so, nodes are arranged in a set of clusters in which one node or more collects data in its cluster and send them after to the next cluster [1].

Table1. Comparison of types

\begin{tabular}{|c|c|c|c|c|}
\hline $\begin{array}{l}\text { Dissemin } \\
\text { ation } \\
\text { Type }\end{array}$ & $\begin{array}{l}\text { Dissemination } \\
\text { Approach }\end{array}$ & Pros & Cons & $\begin{array}{l}\text { Refer } \\
\text { ence }\end{array}$ \\
\hline \multirow[t]{2}{*}{ V2I/I2V } & Push based & $\begin{array}{l}\text { Suitable for } \\
\text { popular data }\end{array}$ & $\begin{array}{l}\text { Unsuitable for } \\
\text { non-popular } \\
\text { data }\end{array}$ & [6] \\
\hline & Pull based & $\begin{array}{l}\text { Suitable for } \\
\text { non-popular } \\
\text { data, user } \\
\text { specific data }\end{array}$ & $\begin{array}{l}\text { cross traffic } \\
\text { incurs heavy } \\
\text { interferences } \\
\text { and collisions }\end{array}$ & {$[1,6]$} \\
\hline \multirow[t]{2}{*}{$\mathrm{V} 2 \mathrm{~V}$} & Flooding & $\begin{array}{l}\text { Data } \\
\text { distribution } \\
\text { is done } \\
\text { quickly and } \\
\text { reliability }\end{array}$ & $\begin{array}{l}\text { Not suitable } \\
\text { for dense } \\
\text { networks }\end{array}$ & [6] \\
\hline & Relaying & $\begin{array}{l}\text { Works well } \\
\text { in dense } \\
\text { networks } \\
\text { and in } \\
\text { congested } \\
\text { networks }\end{array}$ & $\begin{array}{l}\text { Selecting next } \\
\text { best hop and } \\
\text { reliability is } \\
\text { difficult }\end{array}$ & {$[1,6]$} \\
\hline $\begin{array}{l}\text { Opportuni } \\
\text { stic }\end{array}$ & $\begin{array}{l}\text { Store and } \\
\text { forward }\end{array}$ & $\begin{array}{l}\text { Routes are } \\
\text { built } \\
\text { dynamically }\end{array}$ & $\begin{array}{l}\text { It is data } \\
\text { centric } \\
\text { architecture in } \\
\text { which } \\
\text { applications } \\
\text { are not } \\
\text { concerned } \\
\text { with } \\
\text { transporting } \\
\text { data to the } \\
\text { right place. }\end{array}$ & $\begin{array}{l}{[1,9,} \\
10]\end{array}$ \\
\hline $\mathrm{P} 2 \mathrm{P}$ & $\begin{array}{lr}\text { Store } & \text { and } \\
\text { forward } & \text { on } \\
\text { asking } & \end{array}$ & $\begin{array}{l}\text { Works well } \\
\text { in delay } \\
\text { tolerant } \\
\text { applications }\end{array}$ & $\begin{array}{l}\text { Messages are } \\
\text { not sent in the } \\
\text { network }\end{array}$ & $\begin{array}{l}1, \\
11]\end{array}$ \\
\hline $\begin{array}{l}\text { Cluster } \\
\text { based } \\
\text { dissemina } \\
\text { tion }\end{array}$ & $\begin{array}{ll}\text { Clusters are } \\
\text { generated }\end{array}$ & $\begin{array}{l}\text { It provides } \\
\text { high } \\
\text { delivery } \\
\text { ratio and } \\
\text { delay is less }\end{array}$ & $\begin{array}{lr}\text { It does } & \text { not } \\
\text { allow } & \text { all } \\
\text { nodes } & \text { to } \\
\text { broadcast } & \\
\text { messages } & \\
\end{array}$ & $\begin{array}{l}1, \\
11]\end{array}$ \\
\hline
\end{tabular}

\section{FEATURES OF DATA DISSEMINATION PROTOCOLS}

There are some characteristics or features that data dissemination protocols must possess and these features are given below:
a) Scalability
b) Effectiveness
c) Efficiency
d) Dissemination delay
e) Robustness
f) Reliability 


\section{EXISTING DATA DISSEMINATION PROTOCOLS}

Various existing data dissemination protocols are:

\subsection{Urban Multihop Broadcast Protocol:}

This is multihop broadcasting based protocol that uses RTB/CTB handshake approach for sending packets and receiving acknowledgments. Message dissemination is very difficult in urban areas that crowded with tall buildings and number of intersections so there occur line-of-sight problem. So, it becomes mandatory to have techniques or protocols for sending data packets in urban areas. And Urban Multihop broadcast (UMB) protocol is one of them that does directional broadcasting as well as broadcasting at intersections in urban areas [8].

This protocol is designed to address broadcast storm, hidden node and reliability problems in multihop broadcast. The UMB protocol is composed of two phases namely directional broadcast and intersection broadcast.

i) Directional Broadcast: In this method, sender node try to choose the single node (furthest one) in the broadcast direction to assign the duty of forwarding and acknowledging the packets and sender selects the furthest node without knowing the ID or position of its neighbours because nodes change their topology very rapidly due to high mobility. In order to select the furthest node, this protocol divides the road portion within the transmission range into segments. These segments are created only in the direction of propagation. If there is more than one node in the furthest non vacant segment, this segment is further divided into sub segments with smaller widths. The sender node sends Request to broadcast (RTB) packets to all its neighbours in the direction of dissemination then all neighbouring nodes will compute their distance from the source node. Based on this distance, nodes will send energy burst (channel jamming signal) known as black-burst to the source node. More the distance of receiving node from the source node the longest will be black burst. So, length of black-burst is used to select the furthest node and the furthest node sends the longest black burst. Nodes will try to send their black- burst in shortest possible time (SIFS) after they catch the RTB packet. At the end of the black- burst, nodes turn around and pay attention to the channel. If they find the channel unoccupied, it means that their blackburst was longest and they are now responsible to reply with a CTB packet after a duration called CTBTIME. Alternatively, if they find the channel busy, it means that there are some other vehicles further away and they will not send CTB packet. During this process nodes in between can overhear the transmission as well but they cannot access the channel for a time interval specified in RTB and CTB packets. After getting the CTB packet from furthest node, source node will send the broadcast packet to that furthest node. In this broadcast packet, source node contains ID of the node which has successfully sent the CTB packet. This node will be now responsible for forwarding the broadcast packet and sending and acknowledgment (ACK) to the source. And the ACK packet ensures the reliability of packet propagation in the preferred direction [8].

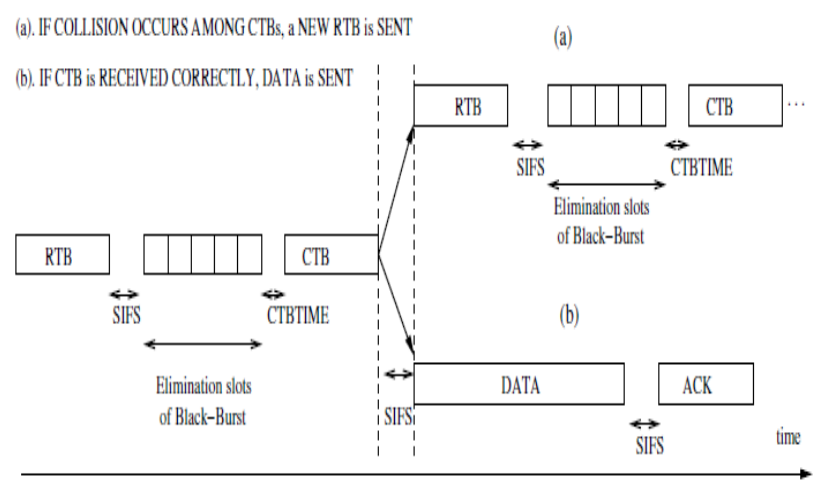

Figure 4: Sequence of packets. (a) Second RTB/CTB handshake (b) DATA/ACK

ii) Intersection Broadcast: The major problem of disseminating data lies in urban areas that are crowded with tall buildings and intersection points and these tall buildings can block communication among vehicles whether they are in transmission range of each other because of line of sight of problem. UMB protocol addresses this problem by installing repeaters at intersections because at intersection points line- of- sight problem is not so effective and repeaters have the best line of sight to the other road segments.

Working of Repeater: When sender node selects a node to forward a packet and it is outside the transmission range of a repeater, working continues in the same manner as in the directional broadcast. On the other hand, if the selected node is inside the transmission range of repeater, the node forwards the packet to the repeater i.e. in this protocol, node will send RTS to the repeater and the repeater will reply with the CTS packet only if the channel is empty. Upon receiving the CTS packet from repeater, the node will send DATA packet to the repeater and transmission halts when node receives an ACK packet from repeater. After receiving this broadcast packet, the repeater initiates a directional broadcast in all road directions except the direction from where it received the packet.

UMB protocol shows very high success percentage even at high packet loads and vehicle traffic densities. And also it makes optimum use of channel (bandwidth) since the forwarding duty is assigned to only one vehicle in the propagation direction. But the limitation of this protocol is cost incurred on installing repeaters and this limitation is eliminated by the AMB protocol which is an adhoc extension of UMB protocol. AMB protocol handles broadcasting at intersections without any repeaters [8]. 


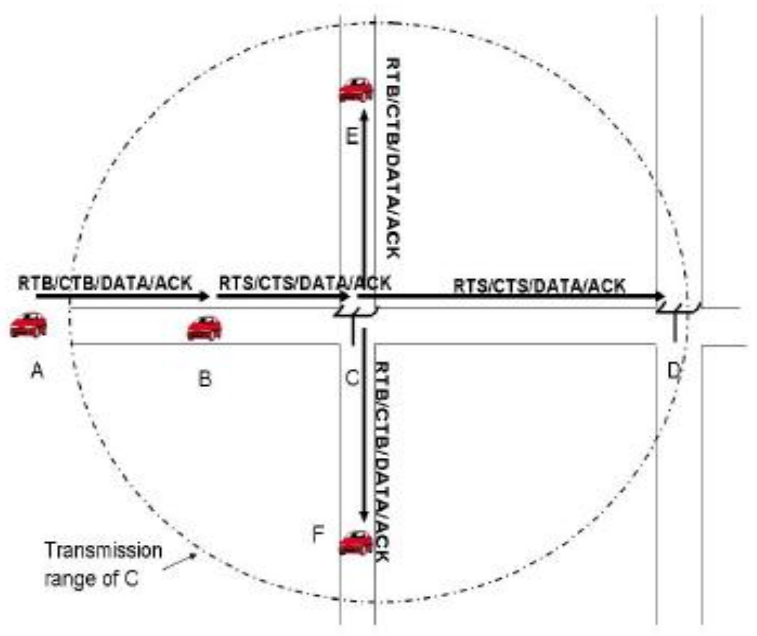

Figure 5: Intersection Broadcast in UMB protocol [8].

\subsection{Ad-Hoc Multihop Broadcast Protocol:}

Ad-hoc Multihop Broadcast (AMB) protocol is an adhoc extension of UMB protocol which handles broadcasts at intersections with the use of repeaters while AMB protocol does not use repeaters at intersections thus eliminating major limitation - infrastructure dependence - of the UMB protocol by employing an efficient intersection broadcast mechanism. In the AMB protocol, directional broadcast is same as that of UMB protocol but in case of Intersection broadcast- vehicles attempt to choose the closest vehicle to the intersection using a fully adhoc algorithm and the chosen vehicle forwards the packet to all road segments except the road segment the packet is received from [12].

Working of AMB Protocol: In this protocol, directional broadcast mechanism is employed of UMB protocol but different intersection broadcast mechanism from that of UMB protocol is proposed where vehicles find the best candidate among themselves to propagate the packets to other road segments. The vehicle closest to the intersection is a good candidate for this function since it is assumed that vehicles closer to the intersections have a better coverage of other road segments [12]. This intersection broadcast mechanism is composed of two phases:

i) Selecting the HUNTER vehicle: The Hunter vehicle tries to select the closest vehicle to the intersection. For this purpose, intersection region will be defined and the first vehicle chosen in the intersection region becomes the Hunter vehicle [12].

ii) Selecting a vehicle for branching the packet propagation: The Hunter vehicle initiates the search to find the closest vehicle to the intersection and in response to this search, vehicles reply with a black-burst according to their distance from the intersection i.e. vehicle closest to the intersection sends the longest black-burst and this new RTB packet is known as Intersection RTB (I-RTB) that is different from the regular RTB employed in directional broadcast in which furthest vehicle from source node sends the longest black-burst. And finally vehicle closest to the intersection becomes responsible for propagating the message to other road segments [12].

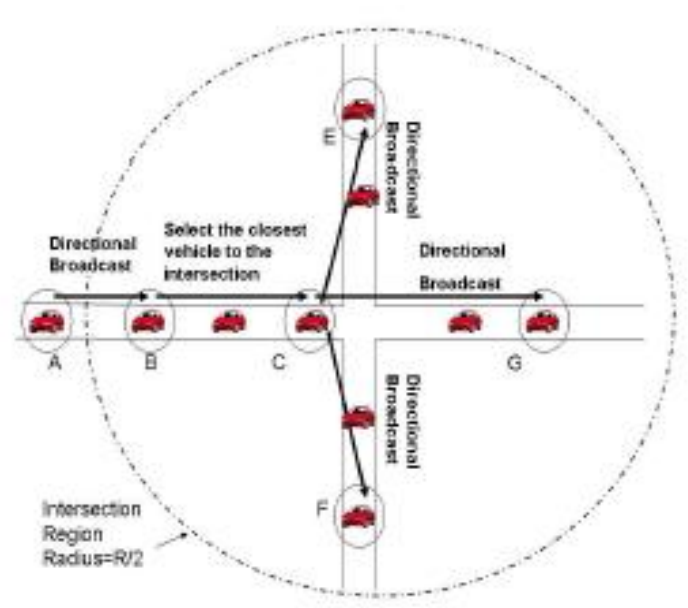

Figure 6: Ad-hoc branching for a simple intersection [12].

\subsection{Acknowledgment-Based Broadcast from Static to highly Mobile Protocol:}

This is broadcast based protocol that is suitable for wide range of vehicular scenarios, which only contains local information acquired by periodic beacon messages. From this information each node can independently decide whether to forward received packet or not. In this protocol, a vehicle that receives a data packet will not forward that packet immediately rather vehicle will check if retransmissions from other neighbors already cover its whole neighborhood in order to avoid redundancy. And this is done by computing Connecting Dominating Set (CDS) of each vehicle. Nodes in the CDS will select a shorter waiting time-out than regular nodes. This allows them to retransmit first if their neighborhood has not been covered before. That is, there are two different techniques, CDS and neighbor elimination scheme (NES). Beacons also contain identifiers of the recently received broadcast messages, which serve as acknowledgments of reception. In this way, nodes can check whether all their neighbors successfully received a message. If this is not the case, a retransmission is scheduled (upon the expiry of timeout duration). Otherwise, retransmission would be redundant. In both cases, when a new neighbor emanates, nodes restart their evaluation time-out if the message being disseminated is not acknowledged. If the message identifier is actually included within the beacon, the neighbor already got the message and no retransmission is scheduled. Hence, the use of acknowledgments makes the protocol more robust to transmission failures while, at the same time, saves redundant retransmissions [13].

\subsection{Bandwidth Efficient Acknowledgment Based Multicasting Protocol:}

Aim of this protocol is to utilize bandwidth efficiently during an emergency situation by minimizing total number of in- 
network message transactions. Bandwidth Efficient Acknowledgment based Multicasting Protocol (BEAM) is created instead of existing broadcasting protocol such as Acknowledgment broadcast from static to highly mobile (ABSM) an adaptive broadcast protocol. BEAM protocol does multicasting instead of broadcasting i.e. instead of doing one to all communication; it transmits the message to only those vehicles that want to receive that message. Road Side Units (RSUs) play a vital role in this protocol [14].

Overview of BEAM Protocol: RSUs will commence the dissemination of packets. First of all RSUs will broadcast join packet to all the vehicles that are in their transmission range. After getting join packet, vehicles that are interested to communicate with RSU will reply back to particular RSU. Now, RSU will create Multicast group that contains all those vehicles that had replied to RSU and all communication will be done between RSU and vehicles in multicast group. Status timer is set by RSU that will probably be of 1 second within that time all vehicles in multicasting group need to tell about their status (i.e. about speed and yaw rate) to RSU, vehicles fail to do this will no longer be part of this group. After getting the status report if it observes sudden increase in speed it means something went wrong and propagate emergency warning message (EWM) to the vehicles in the group and seek acknowledgment from them, if not get acknowledgment within the ack_timer then retransmit the message to particular vehicle so that it can aware about emergency situation and take preventive actions. As emergency messages are multicast instead of broadcast so this protocol utilizes bandwidth efficiently during emergency situations that's why it is known as Bandwidth Efficient Acknowledgment based Multicasting Protocol (BEAM) [14].

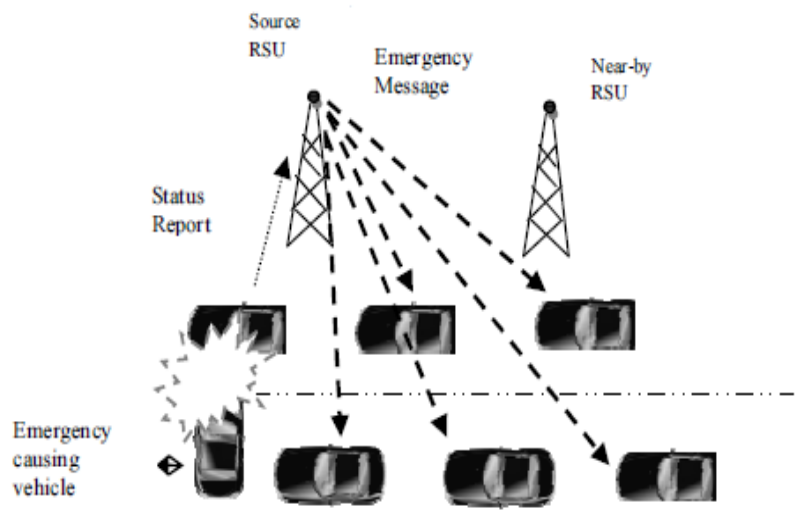

Figure 7: Illustration of an emergency event [14]

\subsection{Adaptive Delay-based Geocast Protocol in Urban VANET:}

Instead of broadcasting, geocasting is used in this paper. Broadcasting means sender node floods the packets to all nodes that are in its communication range that results in broadcast storm problem. In order to avoid this problem, broadcast suppression methods are used that are different in different scenarios and most of the existing suppression methods do not work in urban environments. One existing delay based suppression scheme is adapted in this paper so that making the protocol suitable for urban environments. Broadcast- based geocasting enables efficient data dissemination to vehicles within the given geographical area. Before this protocol, no one has taken into account the urban areas for suppression mechanism. After looking at deep inside it came out that most of existing broadcast suppression methods do not work in urban areas because in urban areas there are several number of intersections and buildings available and buildings can block direct communication of vehicles whether they are in transmission range of each other [15] as shown in figure $8(a)$.

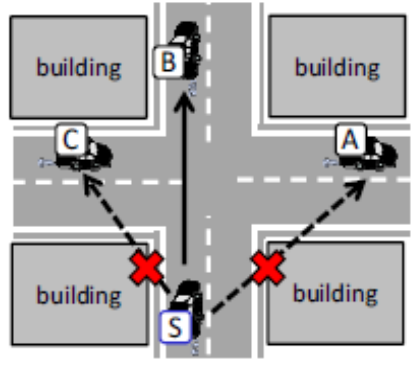

(a) Broadcast on road

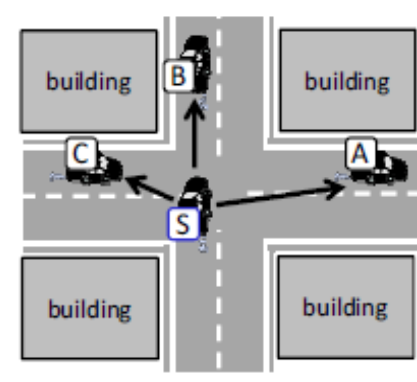

(b) Broadcast at intersection
Figure 8: Broadcasts in urban environment

Now this protocol named Urban Geocast based on Adaptive Delay (UGAD) says that as building are acting as obstacles for data dissemination so there is need to transfer data to those vehicles that can be seen directly; no building or no any other obstacle is there. And more number of vehicles that can be seen directly by source vehicle when source vehicle reaches at intersections. Therefore, according to this protocol opportunity for sending data at intersections should not be missed [15] as shown in figure 8(b).

Working of UGAD: This protocol adapts delay-based scheme for Geocast and urban environments. In order to address the problems in urban scenarios, this protocol increases the opportunity of retransmissions at intersections, by assigning preferential delay values at intersections. Delay values are calculated by the receivers themselves according to their distance from source node and according to their current location [15] (i.e. whether they are at intersections or not) as shown in figure 9 .

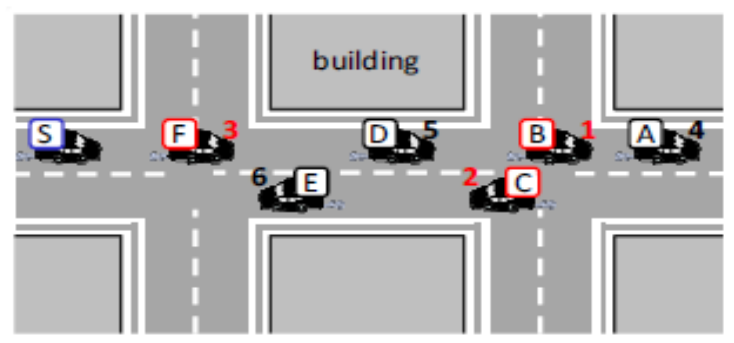

Figure 9: Assignment of delay values [15].

Above figure shows that $\mathrm{S}$ is source node who will broadcast data packet to all vehicles along with the delay values. In ordinary case, farthest vehicle from Source vehicle will have shorter delay value but in case of intersections vehicles at intersections will have shortest delay value and if there is more than one intersection then vehicles at farthest intersection will get lowest delay value. In above figure, no doubt $\mathrm{A}$ is the farthest vehicle from $\mathrm{S}$ but $\mathrm{B}$ is getting lowest delay value because $B$ is at intersection and as at intersections more no. of vehicles can be seen directly so possibility of data to reach its destination increases. There are two forwarding 
modes used for data dissemination in highway and urban environments and these are:

i)

Greedy Forwarding: This forwarding mode is used for reducing redundant rebroadcasts and maximizes the propagation gain. In this case, rebroadcast at intersection is not required. This is particularly used on one dimensional road topology i.e. on highways.

ii) Intersection based forwarding mode: Aim of this mode is to increase the opportunity of vehicles to rebroadcast the packets at intersections which leads to high packet arrival ratio. And vehicles at intersections are assigned preferential back off time values. This mode is particularly used in urban areas that composed of intersections and high buildings.

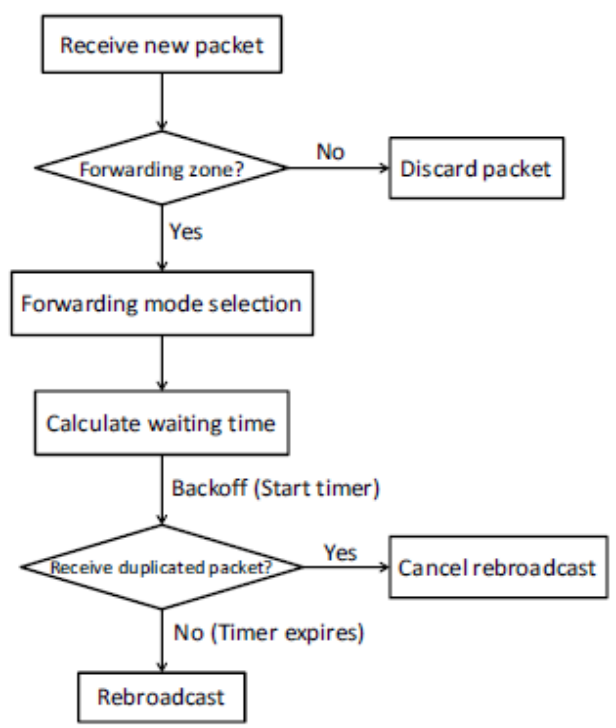

Figure 10: Flowchart of packet processing [15]

Forwarding zone is the zone that is created by source vehicle to propagate the packet to its destination (i.e. at Geocast region). All those nodes that are inside the forwarding zone are allowed to forward the packet while others will discard the packet.

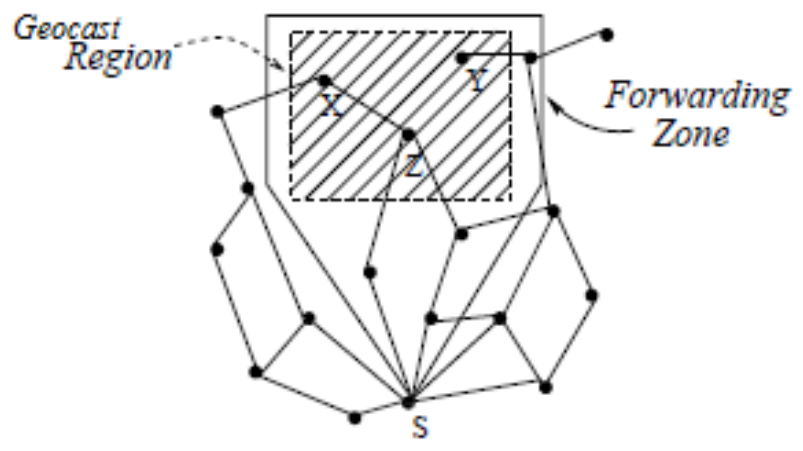

Figure 11: Example of Forwarding Zone

\section{COMPARISON OF EXISTING DATA DISSEMINATION PROTOCOLS}

Table 2. Comparison of data dissemination Protocols

\begin{tabular}{|c|c|c|c|c|c|}
\hline $\begin{array}{l}\text { Existing } \\
\text { Protocol } \\
\text { Name }\end{array}$ & $\begin{array}{l}\text { Mechanism } \\
\text { used }\end{array}$ & Pros & Cons & Urban & Highways \\
\hline UMB & Broadcast & $\begin{array}{l}\text { Saves bandwidth } \\
\text { and reduce } \\
\text { redundancy by } \\
\text { choosing one } \\
\text { vehicle } \\
\text { forwarding tor } \\
\text { packet }\end{array}$ & $\begin{array}{l}\text { Cost incurred } \\
\text { on installing } \\
\text { repeaters that } \\
\text { are used to } \\
\text { forward } \\
\text { packets at } \\
\text { intersections }\end{array}$ & yes & yes \\
\hline AMB & Broadcast & $\begin{array}{lr}\text { saves cost } & \text { as } \\
\text { repeaters are not } \\
\text { used } & \text { at } \\
\text { intersections } & \end{array}$ & $\begin{array}{l}\text { wastage of } \\
\text { time in } \\
\text { finding the } \\
\text { vehicle } \\
\text { closest to } \\
\text { intersection }\end{array}$ & yes & yes \\
\hline ABSM & Broadcast & $\begin{array}{l}\text { It resolves } \\
\text { propagation at } \\
\text { intersection } \\
\text { without } \\
\text { recognising } \\
\text { intersections }\end{array}$ & $\begin{array}{l}\text { Protocol } \\
\text { overhead is } \\
\text { high when } \\
\text { there are } \\
\text { multiple } \\
\text { simultaneous } \\
\text { broadcasting } \\
\text { tasks }\end{array}$ & yes & yes \\
\hline BEAM & Multicast & $\begin{array}{l}\text { bandwidth is } \\
\text { utilized } \\
\text { efficiently during } \\
\text { an emergency } \\
\text { situation and } \\
\text { vehicles decide } \\
\text { themselves } \\
\text { whether to } \\
\text { receive the } \\
\text { message or not }\end{array}$ & $\begin{array}{l}\text { Maintenance } \\
\text { of Multicast } \\
\text { group is } \\
\text { difficult. }\end{array}$ & yes & yes \\
\hline UGAD & Geocast & $\begin{array}{l}\text { Reduce } \\
\text { redundant } \\
\text { rebroadcast and } \\
\text { increases packet } \\
\text { arrival ratio }\end{array}$ & $\begin{array}{l}\text { there is no } \\
\text { method for } \\
\text { assuring that } \\
\text { message has } \\
\text { been reached } \\
\text { to destination } \\
\text { or not }\end{array}$ & yes & yes \\
\hline
\end{tabular}

\section{CONCLUSION}

In this paper, a survey is done on various data dissemination protocols. The literature study shows that there are three types of data dissemination protocols named broadcasting based, multicasting and geocasting based. These protocols reveal that different disseminating techniques are used in different scenarios i.e. some protocols are beneficial for propagating data in urban areas while some are beneficial for highways. Each protocol has its own pros and cons. The survey reveals that to disseminate maximum data over vehicular networks by utilizing minimum bandwidth and to disseminate data in urban areas is a challenging task. These problems are addressed in the reviewed protocols. Each protocol has its own way to deal with these problems. The future idea is to find out the problems of any of these protocols and try to address those found problems.

\section{REFERENCES}

[1] Mor Annu, "Study of Different Type of Data Dissemination Strategy in VANET," International Journal of Engineering Science and Innovative Technology (IJEST), Vol.1, issue2, pp. 6-8, nov-2012

[2] Daraghmi Yousef-Awwad, Yi Chih-Wei, Stojmenovic Ivan, Abdulaziz King, "Forwarding Methods in Data Dissemination and Routing Protocols for Vehicular Ad Hoc Network,” pp. 74-79, IEEE 2013 
[3] Dubey Brij Bihari, Chauhan Naveen, Kumar Prashant, "A Survey on Data Dissemination Techniques used in VANETs," International Journal of Computer Applications, vol.10, issue7, pp. 5-10, nov-2010

[4] Nadeem Tameer, Shankar Pravin, Iftode Liviu, "A Comparative Study of Data Dissemination Models for VANETs", IEEE july-2006

[5] Kakkasageri M.S., Manvi S.S., "Regression based critical information aggregation and dissemination in VANETs: A cognitive agent approach," july 2014

[6] Tomar Pratibha, Chaurasia Brijesh Kumar, Tomar G.S., "State of the Art of Data Dissemination in VANETs," International Journal of Computer Theory and Engineering, Vol.2, No.6, pp. 957-962, Dec-2010

[7] Sushil Kumar, Sudesh Rani, "A Study and Comparative Analysis of Cluster-based data dissemination protocols in VANET", International Journal for Science and Emerging Technologies with Latest Trends (IJSETT), Vol. 14, Issue 1, pp.12-16, March-2014.

[8]Gokhan Korkmaz, Eylem Ekici, "Urban Multi-Hop Broadcast Protocol for Inter-Vehicle Communication Systems", Proc. ACM Int'I. Wksp. Vehicular Adhoc Networks, Philadelphia, PA, Oct-2004.

[9] L.Pelusi, A. Passarella, M. Conti, "Opportunistic Networking: data forwarding in disconnected mobile adhoc networks" Communication Magazines, IEEE Vol.44, Issue 11, pp.134-141, Nov-2006.

[10] Liang Hu, "Mobile Peer-to-Peer Data Dissemination over Opportunistic Wireless Networks" Technical University of Denmark Lyngby, Denmark August, 2009. http://orbit.dtu.dk/fedora/objects/orbit:82647/datastreams /file_5048167/content
[11] Kumar Sushil, Rani Sudesh, "A Study and Comparative Analysis of cluster based data dissemination protocols in VANETs," International Journal for Science and Emerging Technologies with Latest Trends Vol.14, Issue 1, pp. 12-16, 2014

[12] Gokhan Korkmaz, Eylem Ekici and Fusum Ozguner, "An Efficient Fully Ad-Hoc Multi-Hop Broadcast Protocol for Inter- Vehicular Communication Systems", in the proc. of IEEE ICC 2006.

[13] Francisco Javier Ros, Pedro Miguel Ruiz, Ivan Stojmenovic, "Acknowledgment-Based Broadcast Protocol for Reliable and Efficient Data Dissemination in Vehicular Ad Hoc Networks", IEEE Transactions on Mobile Computing, Vol. 11, Issue 1, pp.33-46, Jan-2012.

[14] P.GokulaKrishnan, P.GaneshKumar, "BEAM: Bandwidth Efficient Acknowledgment Based Multicasting Protocol for Sub-Urban Scenario in VANET", Journal of Theoretical and Applied Information Technology (JATIT), Vol. 67, Issue 1, pp.201-211, Sep-2014

[15] Ryosuke Akamatsu, Masaki Suzuki, Takuya Okamoto, Koichiro Hara, Hiroshi Shigeno, "Adaptive Delay- based Geocast Protocol for Data Dissemination in Urban VANET", Proc. of IEEE Seventh International Conference on Mobile Computing and Ubiquitous Networking (ICMU), pp.141-146, 2014.

[16] Rakesh Kumar, Mayank Dave, "A Review of Various VANET Data Dissemination Protocols", International Journal of $\mathrm{u}^{-}$and $\mathrm{e}^{-}$Service, Science and Technology, Vol. 5, Issue 3, pp.27-44,Sep-2012. 